\title{
INFERENCE OF HETEROTIC PROSPECTS FOR ASSORTED MORPHOPHYSIOLOGICAL TRAITS OF WHEAT (TRITICUM AESTIVUM L.) AFTER CROSSING WITH LOCAL LAND RACES
}

\author{
PARVEen, S. $^{1}-$ Hussain, S. B..$^{2 *}$ NOREEN, S. ${ }^{1}-$ ZubaIR, M. ${ }^{3}$ \\ ${ }^{1}$ Institute of Pure and Applied Biology, Bahauddin Zakariya University, Multan, Pakistan \\ ${ }^{2}$ Institute of Molecular Biology and Biotechnology, Bahauddin Zakariya University, Multan, \\ Pakistan \\ ${ }^{3}$ Department of Forestry \& Range Management, Bahauddin Zakariya University, Multan, \\ Pakistan \\ ${ }^{*}$ Corresponding author \\ e-mail:drsyedbilal@hotmail.com \\ (Received $30^{\text {th }}$ Apr 2020; accepted 29 $9^{\text {th }}$ Jul 2020)
}

\begin{abstract}
Manipulation of heterotic potential is considered to be a vital approach for enhancing yield potential of wheat to overcome food security threats. Heterotic potential of ten F1 bread wheat hybrids was estimated for grain yield and contributing traits. Hybrids were developed by crossing five genetically diverse elite wheat lines/varieties with two local land races following line $\times$ tester mating fashion at the regional Agricultural Research Institute, Bahawalpur (Pakistan). The resultant hybrid progenies were grown along with parental genotypes during rabi season 2014-15. Highly significant genetic variability was present in the experimental material for the traits under study. Most of the crosses showed significant heterosis over mid, better and standard parents. Maximum significant commercial heterosis was observed in plant height (27.66\%), followed by tillers per plant (16.67\%), peduncle length (13.59\%) and grain yield per plant $(10.68 \%)$. The highest increase in grain yield per plant over the commercial variety was observed for the cross CB-35 $\times$ LR1 which may be considered for selection as hybrid or pure line wheat varieties for increasing grain yield.
\end{abstract}

Keywords: food security, hybrids, crosses, genetic variation, heterosis

\section{Introduction}

Wheat (Tritium aestivum L.), is the most important crop and among the major three cereal crops that provide staple nutrient source for $40 \%$ of world population (Giraldo et al., 2019) and 20 percent of the total energy requirement in human food (Shewry, 2009). Wheat belongs to the poaceae family, originating from the Levant region of the Near East and Ethiopian Highlands, but now cultivated worldwide (Belderok, 2000). Major cultivated species of wheat include: Triticum aestivum, which is a hexaploid species and is widely cultivated in the world; Triticum durum, the only tetraploid form of wheat widely used today, and the second most widely cultivated wheat; Triticum monococcum, a diploid species with wild and cultivated variants; Triticum dicoccum, a tetraploid species, cultivated in ancient times but no longer has widespread use; Triticum spelta, another hexaploid species, which is cultivated in limited quantities (Moon, 2008). It is used to make flour for leavened, flat and steamed breads and most of the baked foods (Hrivna et al., 2018) and for fermentation to make beer and alcohol (Tsenov et al., 2008).

In Pakistan, wheat is averagely used for about 60 percent of daily diet of common men with average per capita consumption of $125 \mathrm{~kg}$ (Khan et al., 2003). Pakistan is among top 
ten wheat producing countries of the world (Ihsanullah et al., 2002). The contribution of wheat to value addition in agriculture is 8.9 percent, while its contribution to GDP is 1.6 percent (GOP, 2019). Breeding efforts have resulted in various varieties of hexaploid wheat, having improved yield and grain characters. Varieties and advanced lines with different morphological and economic characteristics are now available as breeding stock.

To feed flourishing population of Pakistan; the genetic improvement of wheat genotypes for high yield potential is a dire need. For this purpose, the exploitation of maximum genetic potential from available genetic resources of wheat is a prerequisite. $\mathrm{F}_{1}$ hybrid carrying heterotic effects, which are featured in all crop species, the yield gains are limited to the $F_{1}$ generation. Heterosis is considered as the superiority of the hybrids in comparisons to either of its parents. It is the allelic or non-allelic interaction of genes under the influence of specific environment. Heterosis has been estimated in a range of cultivated crops and has been the purpose of considerable importance to study as mean of increasing productivity of crop plant. It is now well established that heterosis does occur with proper combination of parents. Formerly, utilization of heterotic effects for grain yield was mainly ascribed to cross-pollinated crops. However, later it was reported in wheat as being predominantly self-pollinated for the first time by Freeman (1919), who well-versed the supremacies of $F_{1}$ crosses over their parents (Özgen, 1989). Briggle (1963) described existence of heterosis in substantial quantity for grain yield components in different $F_{1}$ wheat crosses. Keeping in view the above facts, the current research was designed to create genetic diversity and to estimate heterotic potential of crosses among elite lines/varieties with local races of wheat.

\section{Materials and Methods}

The plant materials for study consisted of 7 wheat (Triticum aestivum) genotypes including four strains (CB-35, CB-212, CB-214 and CB-219), one commercial variety (Mairaj-08) and two land races (LR-1 and LR-2) obtained from germplasm resources, Regional Agricultural Research Institute, Bahawalpur (Pakistan). All the genotypes were 99\% pure and true breeding. The selection criteria of crossing lines (dwarf) was based on inducing semi dwarfness in next generation for enhanced yield. Sowing was done in Rabi (Winter crop growing months) season 2013-14, the seeds of each genotype was sown in two rows of $5 \mathrm{~m}$ length each separated by $30 \mathrm{~cm}$. Recommended cultural practices (like fertilization, irrigation, weeding) were carried out during the whole experimental duration. At heading stage, crossing was made following line $\times$ tester fashion by keeping advance strains and commercial variety as lines (female parents) and land races as testers (male parents). Usual method for emasculation and pollination was adopted to prevent self pollination which a major limitation in hybrid production. 10-15 pairs of spikes were crossed to get optimum quantity of $\mathrm{F}_{0}$ seed for each cross. At maturity, crossed spikes were cut, threshed manually, packed and labeled individually for each family.

Ten adjacent plants were tagged from the two central rows ( 5 plants from each row) prior to heading stage from each experimental plot. Data for various morphophysiological traits including plant height, tillers per plant, days to heading, days to anthesis, days to maturity, grain filling period, peduncle length, spike length, grains per spike, grain weight per spike, 1000-grain weight and grain yield per plant were measured from tagged plants at appropriate stage. 


\section{Statistical Analysis}

The analysis of variance was carried out following Steel and Torrie (1980). Significance of differences among genotypes for various plant variables was tested by least significant difference (LSD). Heterosis as compared to mid parent (MP Het.), better parent (BP Het.) and standard parent (SP Het.) as over the commercial variety i.e. Mairaj-08, was estimated using the formulae as

$$
\begin{gathered}
\text { Mid parent heterosis (MP Het. } \left.)=\left(\mathrm{F}_{1}-\text { Mid parent }\right) / \text { Mid parent }\right] \times \\
100
\end{gathered}
$$

(Matzinger et al., 1962)

Better parent heterosis $($ BP Het. $)=\left(\mathrm{F}_{1}-\right.$ Better parent $) /$ Better parent $] \times 100$ (Fonseca and Patterson, 1968)

Standard parent heterosis (MP Het.) $=$

$$
\left.=\left(\mathrm{F}_{1}-\text { Standard parent }\right) / \text { Standard parent }\right] \times 100
$$

(Wynne et al., 1970)

The significance of heterosis was tested by applying t-test according to Wynne et al. (1970).

\section{Results and Discussion}

Analysis of variance revealed significant differences among all the genotypes for various traits under consideration. Variability due to genotypes was spliced into parents and hybrids, both the components also revealed significant variability with respect to all the characters. Parental genotypes were further split into lines and testers, both of which showed significant differences in performance for various morpho-physiological traits under study (Table 1). Mean performance of parents all the genotypes (parents and $\mathrm{F}_{1}$ hybrids) and heterotic potential for various traits under consideration were as is as under.

Table 1. Analysis of variance (mean square values) for various morphophysiological traits in wheat

\begin{tabular}{c|c|c|c|c|c|c|c|c|c|c|c|c|c}
\hline S.O.V & d.f. & $\begin{array}{c}\text { Plant } \\
\text { height }\end{array}$ & $\begin{array}{c}\text { Tillers/Days to } \\
\text { plant }\end{array}$ & $\begin{array}{c}\text { Days to } \\
\text { headinganthesis }\end{array}$ & $\begin{array}{c}\text { Days to } \\
\text { maturity }\end{array}$ & $\begin{array}{c}\text { Grain } \\
\text { filling } \\
\text { period }\end{array}$ & $\begin{array}{c}\text { Peduncle } \\
\text { length }\end{array}$ & $\begin{array}{c}\text { Spike } \\
\text { length }\end{array}$ & $\begin{array}{c}\text { Grains/ } \\
\text { spike }\end{array}$ & $\begin{array}{c}\text { Grain } \\
\text { weight } \\
\text { spike }\end{array}$ & $\begin{array}{c}\text { 1000- } \\
\text { Grain } \\
\text { weight }\end{array}$ & $\begin{array}{c}\text { Grain } \\
\text { yield/ } \\
\text { plant }\end{array}$ \\
\hline Reps. & 2 & 4.137 & 0.137 & 4.941 & 5.353 & 11.353 & 1.118 & 3.843 & 3.078 & 5.706 & 0.129 & 2.431 & 5.471 \\
Genotypes & 16 & 1710.755 & 48.436 & 203.625 & 145.853 & 315.125 & 42.978 & 163.461 & 31.282 & 57.044 & 0.143 & 38.093 & 59.230 \\
Parents & 6 & 3828.714 & 86.413 & 327.857 & 229.714 & 483.191 & 60.429 & 324.714 & 47.079 & 104.857 & 0.030 & 29.714 & 95.937 \\
Crosses & 9 & 458.300 & 26.078 & 142.700 & 105.633 & 232.015 & 33.070 & 59.644 & 10.504 & 28.300 & 0.201 & 19.467 & 38.848 \\
Lines & 4 & 992.383 & 53.550 & 316.200 & 230.550 & 507.950 & 68.450 & 121.283 & 19.967 & 59.550 & 0.310 & 39.133 & 77.950 \\
Testers & 1 & 140.833 & 17.633 & 2.700 & 2.700 & 4.800 & 0.300 & 34.133 & 13.333 & 2.700 & 0.179 & 2.133 & 7.500 \\
L $\times \mathrm{T}$ & 4 & 3.583 & 0.717 & 4.200 & 6.450 & 12.883 & 5.883 & 4.383 & 0.333 & 3.450 & 0.097 & 4.133 & 7.583 \\
Error & 32 & 4.262 & 0.929 & 3.941 & 5.228 & 7.603 & 2.868 & 4.343 & 1.245 & 4.268 & 0.027 & 4.931 & 3.991 \\
\hline
\end{tabular}


Greater plant height is considered an undesirable character due to its positive correlation with lodging and negative relation with earliness. Thus taller plants tend to lodge more resulting in low grain yield (Mazurek and Sabat, 1984). Introduction of Rht dwarfing genes in tall stature wheat varieties resulted semi-dwarf varieties responsive to inputs which brought green revolution in 1960's. In present studies, parental genotypes which were used as females were short to semi dwarf statured ranging from $42 \mathrm{~cm}$ (CB-212) to $94 \mathrm{~cm}$ (Mairaj-08) as compared to males (LR-1 $122.00 \mathrm{~cm}$ and LR-2 $128.00 \mathrm{~cm}$ tall) (Table 2, Fig. 1).

Table 2. Mean performance with LSD of parents and crosses for various morphophysiological traits in wheat

\begin{tabular}{c|cc|cc|cc|cc|cc|cc}
\hline Genotype & Plant height & Tillers/plant & \multicolumn{2}{|c|}{$\begin{array}{c}\text { Days to } \\
\text { heading }\end{array}$} & \multicolumn{2}{c|}{$\begin{array}{c}\text { Days to } \\
\text { anthesis }\end{array}$} & Days to maturity & Grain filling period \\
\hline CB-35 & 56.00 & M & 15.67 & BC & 99.00 & HI & 113.00 & GH & 136.00 & JK & 23.00 & EF \\
CB-212 & 42.00 & O & 17.33 & A & 126.00 & A & 136.00 & A & 168.00 & A & 32.00 & AB \\
CB-214 & 48.00 & N & 16.00 & AB & 110.00 & EF & 120.00 & EF & 150.00 & FGH & 30.00 & BCD \\
CB-219 & 61.00 & L & 14.33 & CD & 106.00 & G & 121.00 & EF & 144.33 & I & 23.33 & EF \\
Mairaj-08 & 94.00 & E & 12.00 & FGH & 96.00 & I & 110.00 & H & 132.00 & K & 22.00 & F \\
LR-1 & 122.00 & B & 5.67 & J & 112.00 & DE & 121.00 & EF & 151.00 & EFG & 30.00 & BCD \\
LR-2 & 128.00 & A & 3.67 & K & 118.00 & BC & 128.00 & BC & 160.00 & BC & 32.00 & AB \\
CB-35 $\times$ LR1 & 74.00 & IJ & 13.00 & DEF & 110.00 & EF & 120.00 & EF & 151.00 & EFG & 31.00 & ABC \\
CB-35 $\times$ LR2 & 78.00 & H & 12.00 & FGH & 113.00 & DE & 123.00 & DE & 155.00 & DE & 32.00 & AB \\
CB-212 $\times$ LR1 & 68.00 & K & 14.00 & D & 119.00 & B & 129.00 & B & 162.00 & B & 33.00 & A \\
CB-212 $\times$ LR2 & 71.00 & JK & 12.33 & EFG & 118.00 & BC & 130.00 & B & 161.00 & B & 31.00 & ABC \\
CB-214 $\times$ LR1 & 75.00 & HI & 13.67 & DE & 114.00 & D & 125.00 & CD & 154.00 & DEF & 29.00 & CD \\
CB-214 $\times$ LR2 & 82.00 & G & 11.33 & GH & 115.00 & CD & 127.00 & BC & 156.33 & CD & 29.33 & BCD \\
CB-219 $\times$ LR1 & 90.00 & F & 10.67 & H & 108.00 & FG & 120.00 & EF & 149.33 & GH & 29.33 & BCD \\
CB-219 $\times$ LR2 & 94.00 & E & 8.67 & I & 107.00 & FG & 118.00 & F & 146.00 & HI & 28.00 & D \\
Mairaj-08 $\times$ LR1 & 99.33 & D & 6.33 & J & 99.00 & HI & 114.00 & G & 136.00 & JK & 22.00 & F \\
Mairaj-08 $\times$ LR2 & 103.00 & C & 5.67 & J & 100.00 & H & 113.00 & GH & 138.00 & J & 25.00 & E \\
\hline
\end{tabular}

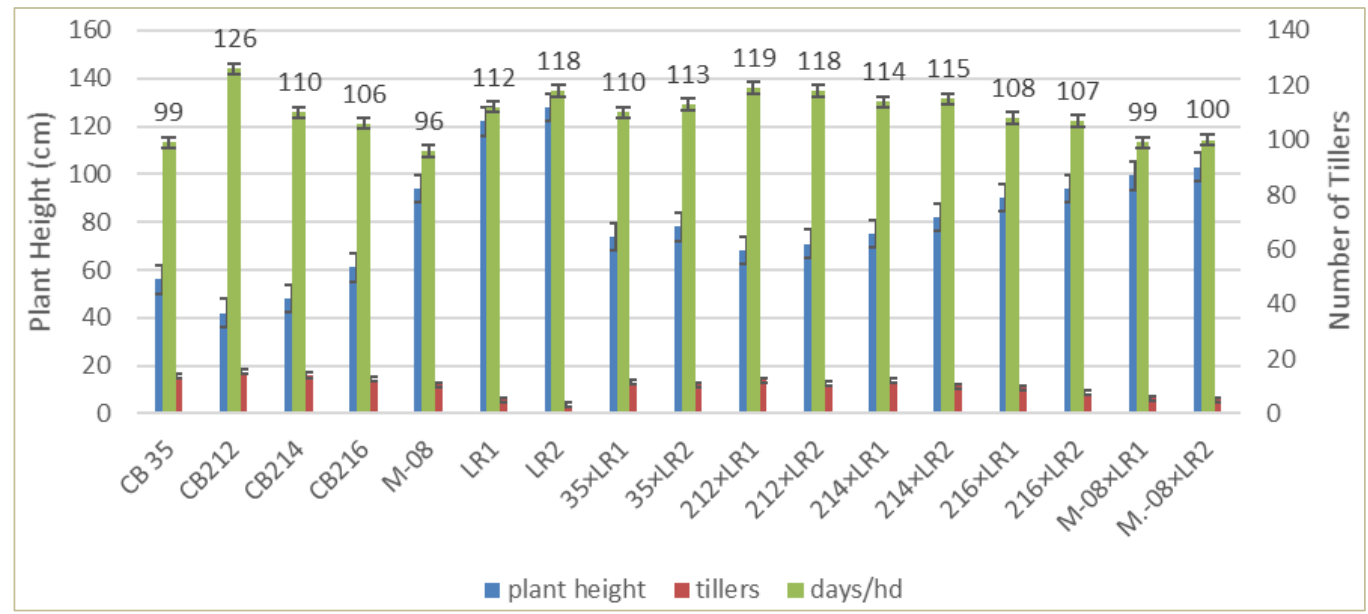

Figure 1. Mean performance of parents and crosses for plant height, tiller per plant and days to heading 
All the $\mathrm{F}_{1}$ crosses lied in between the range of parental genotypes with respect to plant height. CB-212 $\times$ LR-1, among F1 crosses, was at the lowest position regarding height while maximum height was recorded for the cross Mairaj-08 $\times$ LR-2 $(103.00 \mathrm{~cm})$ (Table 2, Fig. 1).

Lower value of number of days taken to $50 \%$ heading is directly related to earliness and vice versa. In present studies, parental genotypes which were used as females were ranging between $96.00 \mathrm{~cm}$ (Mairaj-08) to 126.00 (CB-212). While the male parents LR-1 and LR-2 were $112.00 \mathrm{~cm}$ and $118.00 \mathrm{~cm}$, respectively (Table 2 and Fig. 1).

All the $F_{1}$ crosses lied in between the range of parental genotypes with respect to number of days to $50 \%$ heading. Mairaj- $08 \times$ LR-1, among $\mathrm{F}_{1}$ crosses, showed the minimum number of days for 50\% heading (99) and hence was considered as the most favorable cross regarding earliness, closely followed by Mairaj-08 $\times$ LR-2 (100) (Table 2). While maximum days to heading were observed for the cross CB-212 $\times$ LR-1 (119.00) (Table 2 and Fig. 1).

Days to anthesis are also a parameter related to short or long duration for maturity. It is also most affected by the environmental conditions. Maximum days to anthesis were taken by the line CB-212 i.e. 136 days while minimum days to anthesis were recorded for Mairaj-08 (110 days) (Table 2, Fig. 2). The results indicated Mairaj-08 as the favorable parent regarding earliness with respect to number of days taken for anthesis. Among male parents, LR-1 showed early anthesis (121 days) as compared to LR-2 which took 128 days (Table 2 and Fig. 2).

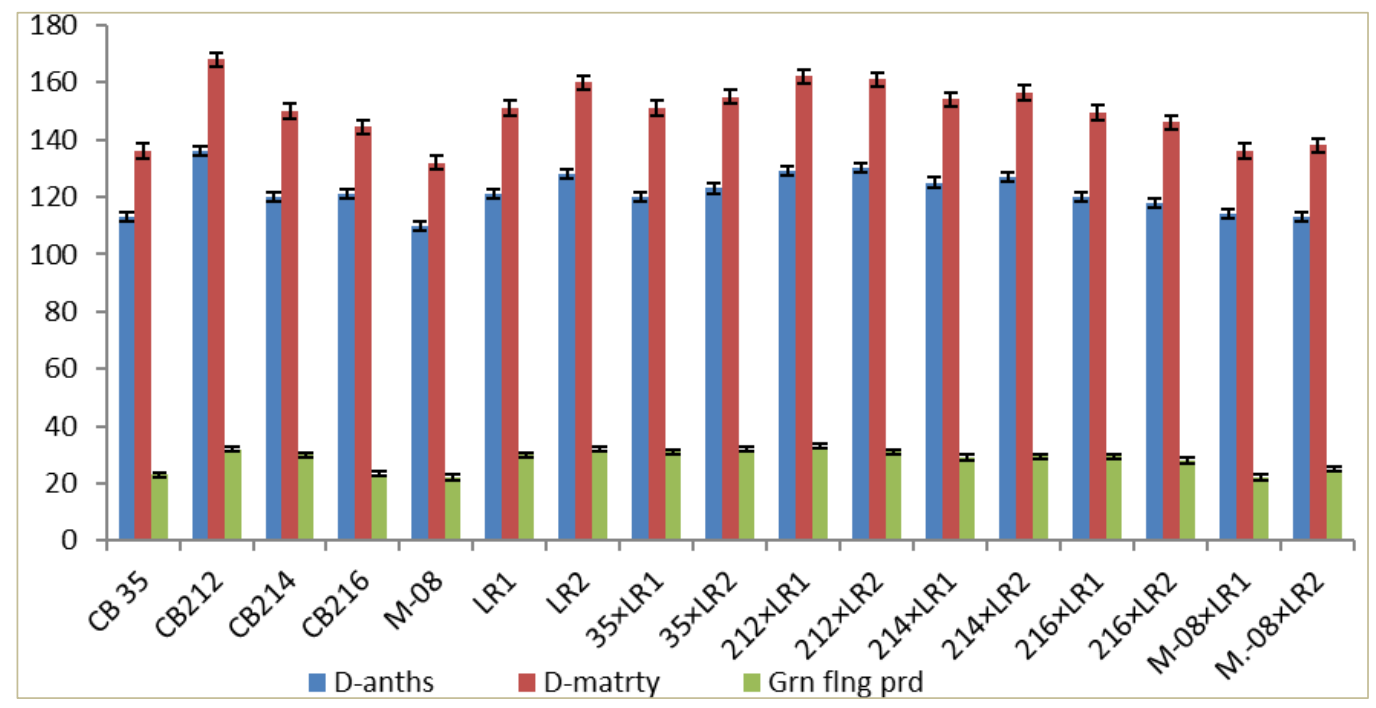

Figure 2. Mean performance of parents and crosses for days to anthesis, days to maturity and grain filling period

In some crosses where heterobeltiosis was observed over dominance might be involved and it may be concluded that effective selection of desirable recombinants from this material is possible. These results are in accordance with the previous findings (Sadeque et al., 1991; Ullah et al., 2006; Akbar et al., 2007) who also reported negative heterosis for plant height.

More tillers per plant results in more spikes per plant which increases the grain yield per plant. More tillering capacity was observed in lines ranging from 12.00 to 17.33 tillers 
as compared to testers (3.67 - 5.67 tillers per plant) (Table 2, Fig. 1). CB-212 produced the highest number of tillers per plant followed by CB-214 with 16.00 tillers while Mairaj08 produced relatively lower number of tillers per plant (12.00) (Table 2 and Fig. 1).

All the $F_{1}$ crosses lied in between the range of parental genotypes with respect to tillers per plant, Mairaj- $08 \times \mathrm{LR}-2$, among $\mathrm{F}_{1}$ crosses, was at the lowest position regarding tillers per plant while maximum tillers per plant was recorded for the cross CB-214 $\times$ LR-1 (14.00) (Table 2 and Fig. 1).

All the $F_{1}$ crosses lied in between the range of parental genotypes with respect to days to anthesis. Mairaj-08 $\times$ LR-2, took the lowest number of days regarding the trait (113.00), closely followed by Mairaj-08 $\times$ LR-1 $(114.00 \mathrm{~cm})$. CB-212 $\times$ LR-2 took the maximum number of days to anthesis (130 days), closely followed by CB-212 $\times$ LR-1 with 129 days to anthesis (Table 2 and Fig. 2).

Days to maturity is the parameter directly related to crop duration whether early or late. A genotype taking more number of days to maturity is long duration and vice versa. Less number of days taken to maturity is desirable character. In current studies, among parental genotypes which were used as females, Mairaj-08 was the most early maturing with minimum days to maturity (132) followed by CB-35 which took 136 days to reach maturity (Table 2, Fig. 2). While CB-212 was recorded as the longest durational genotype taking 168 days to reach maturity (Table 2, Fig. 2). CB-214 and CB-219 took 150 and 144.33 days respectively, to reach their maturity stage (Table 2, Fig. 2). Among testers, LR-1 took 151 days while LR-2 took 160 days for maturity (Table 2 and Fig. 2).

Range of $F_{1}$ crosses regarding number of days to maturity was recorded as 136 to 162 which are in between the two extremes of the parents for the concerned trait. Cross of Mairaj-08 with LR-1 and LR-2 were considered as the early maturing hybrids with 136 and 138 days taken to maturity, respectively (Table 2 and Fig. 2). On the other hand, CB-212 $\times$ LR-1 took the maximum number of days to maturity with a value of 162 days, closely followed by CB-212 $\times$ LR-2 (161 days) (Table 2 and Fig. 2).

Days taken for grain filling are also an important determinant of earliness or lateness of a variety or genotype. However it is also largely influenced by the environmental conditions. Minimum grain filling period was observed in Mairaj-08 (22 days), closely followed by CB-35 and CB-219 with values 23.0 and 23.33, respectively (Table 2, Fig. 2). CB-212 took the maximum days for grain filling i.e. 32 days, followed by CB-214 which required 30 days for filling of grains. While the testers LR-1 and LR-2 took 30 and 32 days period for grain filling (Table 2 and Fig. 2).

In present studies, parental genotypes which were used as females were short statured for peduncle length ranging from $20 \mathrm{~cm}$ (CB-212) to $36 \mathrm{~cm}$ (Mairaj-08) as compared to males (LR-1 $44 \mathrm{~cm}$ and LR-2 $47 \mathrm{~cm}$ tall) (Table 3 and Fig. 3).

All the $F_{1}$ crosses lied in between the range of parental genotypes with respect to peduncle length. CB-212 $\times$ LR-1, among $F_{1}$ crosses, was at the lowest position regarding peduncle length while maximum peduncle length was recorded for the cross Mairaj-08 $\times$ LR-1 (41.00) (Table 3 and Fig. 3).

Almost half of the F1 hybrids showed increase in peduncle length over mid parental value but this increase was non-significant. All the crosses revealed heterobeltosis towards negative (lower) side, minimal decrease in peduncle length was recorded for the cross Mairaj- $08 \times$ LR-1 (Table 4). Above mentioned cross also gave the highest heterotic value of $13.89 \%$ for peduncle length over the standard parent (Table 4). These outcomes are in agreement with those of Farooque et al. (2005), Masood et al. (2005) and Ilker et 
al. (2010) who advocated that long peduncle has positive direct effect on grain yield due to its photosynthetic activity.

Table 3. Mean performance with LSD of parents and crosses for various morphophysiologicaltraits in wheat

\begin{tabular}{|c|c|c|c|c|c|c|c|c|c|c|c|c|}
\hline \multirow{2}{*}{$\begin{array}{c}\text { Genotype } \\
\text { CB-35 }\end{array}$} & \multicolumn{2}{|c|}{$\begin{array}{c}\text { Peduncle } \\
\text { length }\end{array}$} & \multicolumn{2}{|c|}{$\begin{array}{l}\text { Spike } \\
\text { length }\end{array}$} & \multicolumn{2}{|c|}{ Grains/spike } & \multicolumn{2}{|c|}{$\begin{array}{c}\text { Grain } \\
\text { weight/spike }\end{array}$} & \multicolumn{2}{|c|}{$\begin{array}{c}\text { 1000-Grain } \\
\text { weight }\end{array}$} & \multicolumn{2}{|c|}{$\begin{array}{c}\text { Grain } \\
\text { yield/plant }\end{array}$} \\
\hline & 26.00 & JK & 16.33 & A & 44.00 & BCDE & 2.42 & A & 41.00 & A & 35.33 & $\mathrm{ABCD}$ \\
\hline CB-212 & 20.00 & $\mathrm{~L}$ & 17.00 & A & 42.00 & DEFG & 2.35 & $\mathrm{AB}$ & 38.00 & $\mathrm{ABCD}$ & 37.67 & A \\
\hline CB-214 & 23.00 & KL & 11.67 & B & 46.00 & $\mathrm{ABC}$ & 2.26 & $\mathrm{ABC}$ & 35.00 & DEFG & 36.00 & $\mathrm{ABC}$ \\
\hline CB-219 & 30.00 & $\mathrm{HI}$ & 9.33 & $\mathrm{CDE}$ & 47.00 & $\mathrm{AB}$ & 2.40 & $\mathrm{AB}$ & 40.00 & $\mathrm{AB}$ & 35.33 & $\mathrm{ABCD}$ \\
\hline Mairaj-08 & 36.00 & DEF & 11.00 & $\mathrm{BC}$ & 49.00 & A & 2.36 & $\mathrm{AB}$ & 39.00 & $\mathrm{ABC}$ & 34.33 & BCDE \\
\hline LR-1 & 44.00 & $\mathrm{AB}$ & 8.00 & EFG & 36.00 & JK & 2.27 & $\mathrm{ABC}$ & 36.00 & $\mathrm{CDEF}$ & 27.67 & $\mathrm{G}$ \\
\hline LR-2 & 47.00 & A & 6.67 & FGH & 33.00 & K & 2.13 & $\mathrm{BC}$ & 32.00 & GH & 22.00 & $\mathrm{H}$ \\
\hline $\mathrm{CB}-35 \times \mathrm{LR} 1$ & 30.33 & $\mathrm{HI}$ & 10.00 & $\mathrm{BCD}$ & 42.00 & DEFG & 2.30 & $\mathrm{ABC}$ & 37.00 & $\mathrm{BCDE}$ & 38.00 & A \\
\hline $\mathrm{CB}-35 \times \mathrm{LR} 2$ & 34.00 & FG & 9.00 & DE & 40.00 & FGHI & 2.29 & $\mathrm{ABC}$ & 35.00 & DEFG & 36.00 & $\mathrm{ABC}$ \\
\hline CB-212 $\times$ LR 1 & 28.00 & IJ & 11.67 & $\mathrm{~B}$ & 38.00 & HIJ & 2.26 & $\mathrm{ABC}$ & 34.00 & EFGH & 37.00 & $\mathrm{AB}$ \\
\hline $\mathrm{CB}-212 \times \mathrm{LR} 2$ & 32.00 & $\mathrm{GH}$ & 10.00 & $\mathrm{BCD}$ & 39.00 & GHIJ & 2.30 & $\mathrm{ABC}$ & 33.00 & FGH & 36.33 & $\mathrm{ABC}$ \\
\hline CB-214 × LR 1 & 35.00 & EFG & 7.67 & $\mathrm{EFGH}$ & 46.00 & $\mathrm{ABC}$ & 1.46 & D & 28.00 & I & 37.67 & A \\
\hline CB-214 $\times$ LR2 & 37.00 & DEF & 6.67 & FGH & 45.00 & $\mathrm{BCD}$ & 2.06 & $\mathrm{C}$ & 30.33 & HI & 33.33 & $\mathrm{CDE}$ \\
\hline CB-219 $\times$ LR 1 & 38.00 & $\mathrm{CDE}$ & 8.33 & DEF & 43.00 & CDEF & 2.20 & $\mathrm{ABC}$ & 34.00 & EFGH & 31.67 & $\mathrm{EF}$ \\
\hline CB-219 $\times$ LR2 & 39.00 & $\mathrm{CD}$ & 6.33 & $\mathrm{GH}$ & 41.00 & EFGH & 2.22 & $\mathrm{ABC}$ & 33.00 & FGH & 32.67 & $\mathrm{DE}$ \\
\hline $\begin{array}{l}\text { Mairaj-08 } \times \\
\text { LR1 }\end{array}$ & 41.00 & $\mathrm{BC}$ & 7.00 & FGH & 37.00 & IJ & 2.19 & $\mathrm{ABC}$ & 32.00 & $\mathrm{GH}$ & 28.00 & $\mathrm{G}$ \\
\hline $\begin{array}{c}\text { Mairaj-08 } \times \\
\text { LR2 }\end{array}$ & 41.00 & $\mathrm{BC}$ & 6.00 & $\mathrm{H}$ & 38.00 & HIJ & 2.32 & $\mathrm{ABC}$ & 31.00 & $\mathrm{HI}$ & 29.00 & FG \\
\hline
\end{tabular}

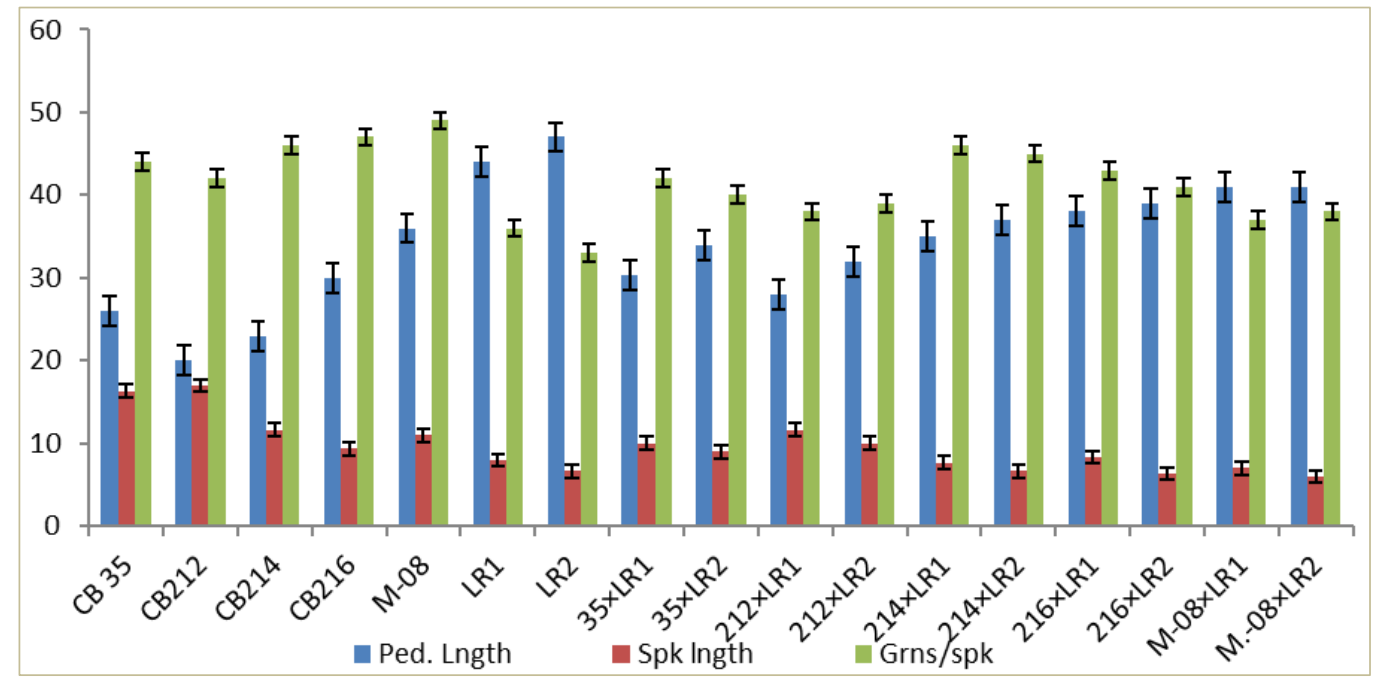

Figure 3. Mean performance of parents and crosses for peduncle length, spike length and grains per spike 
Table 4. Heterosis percentage over mid parent, better parent and standard variety (Mairaj-08) for days to maturity, grain filling period, peduncle length and spike length in wheat

\begin{tabular}{|c|c|c|c|c|c|c|c|c|c|c|c|c|}
\hline \multirow{2}{*}{ CROSS } & \multicolumn{3}{|c|}{ Days to maturity } & \multicolumn{3}{|c|}{ Grain filling period } & \multicolumn{3}{|c|}{ Peduncle length } & \multicolumn{3}{|c|}{ Spike length } \\
\hline & MP Het. & BP Het. & SP Het. & MP Het. & BP Het. & SP Het. & MP Het. & BP Het. & SP Het. & MP Het. & BP Het. & SP Het. \\
\hline $\mathrm{CB}-35 \times \mathrm{LR} 1$ & $5.23 * *$ & $0.00^{\mathrm{NS}}$ & $14.39 * *$ & $16.98 * *$ & $3.33^{\mathrm{NS}}$ & $40.91 * *$ & $-13.33^{* *}$ & $-31.06 * *$ & $-15.74 * *$ & $-17.81 * *$ & $-38.78 * *$ & $-9.09^{\mathrm{NS}}$ \\
\hline $\mathrm{CB}-35 \times \mathrm{LR} 2$ & $4.73 * *$ & $-3.13^{*}$ & $17.42 * *$ & $16.36^{* *}$ & $0.00^{\mathrm{NS}}$ & $45.45^{* *}$ & $-6.85^{\mathrm{NS}}$ & $-27.66^{* *}$ & $-5.56^{\mathrm{NS}}$ & $-21.74 * *$ & $-44.90 * *$ & $-18.18 *$ \\
\hline $\mathrm{CB}-212 \times \mathrm{LR} 1$ & $1.57^{\mathrm{NS}}$ & $-3.57 *$ & $22.73 * *$ & $6.45^{\mathrm{NS}}$ & $3.13^{\mathrm{NS}}$ & $50.00 * *$ & $-12.50 * *$ & $-36.36^{* *}$ & $-22.22 * *$ & $-6.67^{\mathrm{NS}}$ & $-31.37 * *$ & $6.06^{\mathrm{NS}}$ \\
\hline $\mathrm{CB}-212 \times \mathrm{LR} 2$ & $-1.83^{\mathrm{NS}}$ & $-4.17 * *$ & $21.97 * *$ & $-3.13^{\mathrm{NS}}$ & $-3.13^{\mathrm{NS}}$ & $40.91^{* *}$ & $-4.48^{\mathrm{NS}}$ & $-31.91 * *$ & $-11.11 *$ & $-15.49 *$ & $-41.18^{* *}$ & $-9.09^{\mathrm{NS}}$ \\
\hline CB-214 × LR1 & $2.33^{\mathrm{NS}}$ & $1.99^{\mathrm{NS}}$ & $16.67 * *$ & $-3.33^{\mathrm{NS}}$ & $-3.33^{\mathrm{NS}}$ & $31.82 * *$ & $4.48^{\mathrm{NS}}$ & $-20.45^{* *}$ & $-2.78^{\mathrm{NS}}$ & $-22.03 * *$ & $-34.29 * *$ & $-30.30 * *$ \\
\hline $\mathrm{CB}-214 \times \mathrm{LR} 2$ & $0.86^{\mathrm{NS}}$ & $-2.29^{\mathrm{NS}}$ & $18.43 * *$ & $-5.38^{\mathrm{NS}}$ & $-8.33^{\mathrm{NS}}$ & $33.33 * *$ & $5.71^{\mathrm{NS}}$ & $-21.28 * *$ & $2.78^{\mathrm{NS}}$ & $-27.27 * *$ & $-42.86 * *$ & $-39.39 * *$ \\
\hline CB-219 × LR1 & $1.13^{\mathrm{NS}}$ & $-1.10^{\mathrm{NS}}$ & $13.13 * *$ & $10.00 *$ & $-2.22^{\mathrm{NS}}$ & $33.33 * *$ & $2.70^{\mathrm{NS}}$ & $-13.64 * *$ & $5.56^{\mathrm{NS}}$ & $-3.85^{\mathrm{NS}}$ & $-10.71^{\mathrm{NS}}$ & $-24.24 * *$ \\
\hline CB-219 × LR2 & $-4.05 * *$ & $-8.75 * *$ & $10.61 * *$ & $1.20^{\mathrm{NS}}$ & $-12.50 * *$ & $27.27 * *$ & $1.30^{\mathrm{NS}}$ & $-17.02 * *$ & $8.33^{\mathrm{NS}}$ & $-20.83^{*}$ & $-32.14 * *$ & $-42.42 * *$ \\
\hline Mairaj-08 × LR1 & $-3.89 * *$ & $-9.93 * *$ & $3.03^{\mathrm{NS}}$ & $-15.38 * *$ & $-26.67 * *$ & $0.00^{\mathrm{NS}}$ & $2.50^{\mathrm{NS}}$ & $-6.82^{\mathrm{NS}}$ & $13.89 * *$ & $-26.32 * *$ & $-36.36 * *$ & $-36.36 * *$ \\
\hline Mairaj-0 $8 \times$ LR2 & $-5.48 * *$ & $-13.75^{* *}$ & $4.55^{*}$ & $-7.41^{\mathrm{NS}}$ & $-21.88^{* *}$ & $13.64 *$ & $-1.20^{\mathrm{NS}}$ & $-12.77 * *$ & $13.89 * *$ & $-32.08 * *$ & $-45.45 * *$ & $-45.45 * *$ \\
\hline
\end{tabular}

$* * *$ is equal to significant at $0.01,0.001$ respectively and NS showing non significant 
Longer spike having more spikelets is usually, not always, considered associated with higher seed number per spike and ultimately the yield. The highest spike length, among lines, was observed in CB-212 $(17.00 \mathrm{~cm})$, followed by CB-35 with $16.33 \mathrm{~cm}$ average spike length (Table 3). Minimum spike length was recorded for the genotype CB-219 $(9.33 \mathrm{~cm})($ Table 3). CB-214 and Mairaj-08 produced spikes of 11.67 and $11.00 \mathrm{~cm}$ length respectively. Both the testers, LR-1 and LR-2 produced shorter spikes with average length of 8.00 and 6.67, respectively (Table 3 and Fig. 3).

Character of grains per spike is considered one of the major directly related yield components. Greater the number of grains per spike, greater will be the yield and vice versa. In present studies, parental genotypes which were used as females were showed a range of 42 to 49 . Mairaj-08 gave the highest number of grains per spike followed by CB-219 (47). On the other hand CB-212 gave the least number of grains per spike (42). Among male parents LR-1 produced 36 grains per spike while LR-2 showed 33 grains per spike (Table 3 and Fig. 3).

All the $F_{1}$ crosses lied in between the range of parental genotypes with respect to grains per spike. CB-214 $\times$ LR-1 was the most desirable cross as it produced the maximum grains per spike (46), followed by CB-214 × LR-2 (45) (Table 3, Fig. 3). While Mairaj-08 $\times$ LR-1 performed poor with respect to the character as it produced the lowest grains per spike (37), followed by Mairaj-08 $\times$ LR-2 and CB-212 $\times$ LR-1 which produced equal number of grains per spike (38) (Table 3 and Fig. 3).

A range of $6.00 \mathrm{~cm}$ to $11.67 \mathrm{~cm}$ regarding spike length was recorded in $F_{1}$ population. CB-212 $\times$ LR-1 was considered the most favorable cross for higher spike length which produced spikes of $11.67 \mathrm{~cm}$ length (Table 3, Fig. 3). CB-212 $\times$ LR-2 and CB-35 $\times$ LR-1 produced spike of equal length of $10.00 \mathrm{~cm}$. While the lowest spike length was observed in Mairaj-08 $\times$ LR-2 $(6.00 \mathrm{~cm})$, followed by CB-214 $\times$ LR-2 with $6.67 \mathrm{~cm}$ spike length (Table 3).

Maximum grain weight per spike was recorded for the line CB-35 (2.42 g), followed by CB-219 showed $2.40 \mathrm{~g}$ weight of grains per spike. While the lines Mairaj-08, CB-212 and CB-219 gave $2.36 \mathrm{~g}, 2.35 \mathrm{~g}$ and $2.26 \mathrm{~g}$ weight of grains per spike (Table 3, Fig. 4). While LR-1 and LR-2 produced $2.27 \mathrm{~g}$ and $2.13 \mathrm{~g}$ grain weight per spike (Table 3 and Fig. 4).

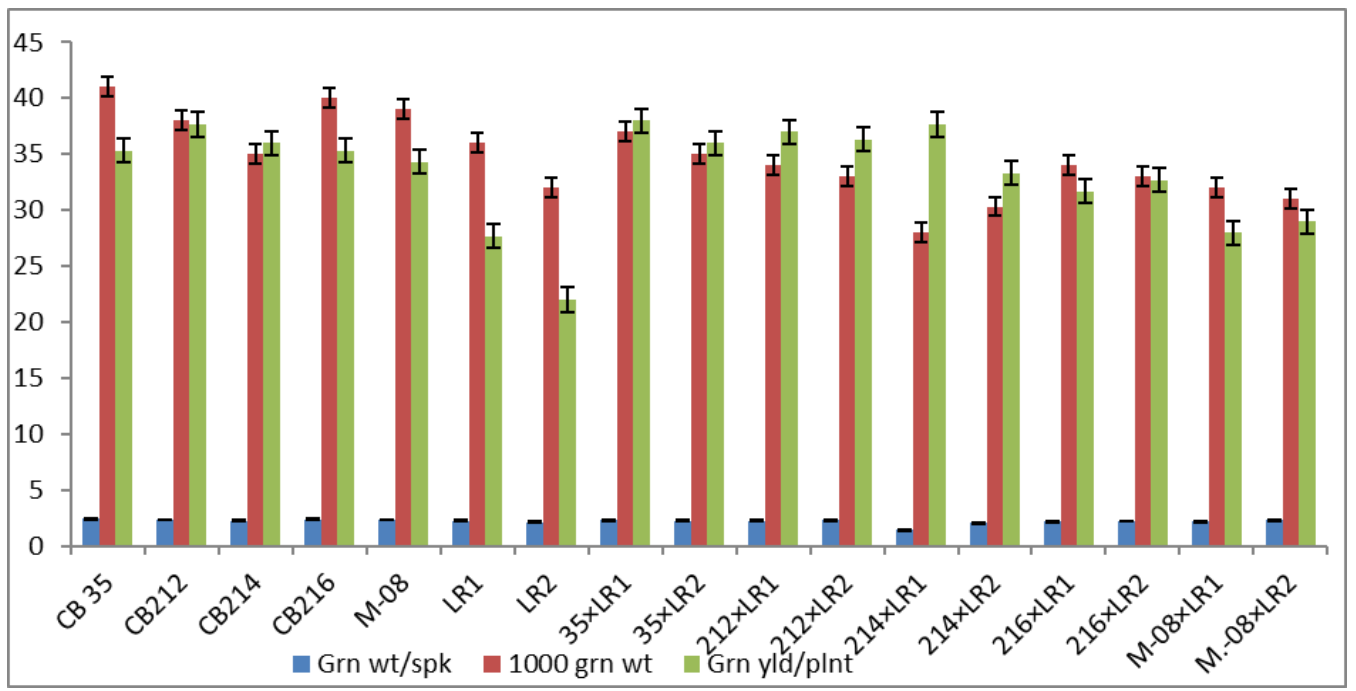

Figure 4. Mean performance of parents and crosses for grain weight per spike, 1000 grain weight and grain yield per plant 
Critical analysis of the data of mean performance of $F_{1}$ hybrids regarding grain weight per spike revealed that the cross Mairaj- $08 \times$ LR-2 produced the maximum grain weight per spike (2.32 g) (Table 3, Fig. 3). CB-35 $\times$ LR-1 and CB-212 $\times$ LR-2 showed equal value of $2.30 \mathrm{~g}$ for grain weight per spike. While CB-214 $\times$ LR-1 produced the lowest weight for grains per spike (1.46 g) (Table 3 and Fig. 3).

All the $F_{1}$ crosses lied in between the range of parental genotypes with respect to 1000-grain weight. CB-214 $\times$ LR-1, among $F_{1}$ crosses, was at the lowest position regarding 1000-grain weight while maximum 1000-grain weight was recorded for the cross CB-35 $\times$ LR-1 (37.00) (Table 3, Fig. 4). All the crosses showed negative values for all three types of heterosis i.e. mid, better and standard parent. However CB-35 $\times$ LR-1 exhibited minimum decrease in 1000-grain weight in relation with mid (3.90\%), better $(9.76 \%)$ and standard parent $(5.13 \%)$ (Table 5). Similar observations have been reported by Saleem and Hussain (1988), Abdullah et al. (2003), Hassan et al. (2007), Kumar et al. (2013) and Mahpara et al. (2015).

More tillers per plant results in more spikes per plant which increases the grain yield per plant. More grain yield per plant was observed in lines ranging from 37.67 to 34.33 as compared to testers $(27.67-22.00)$. CB-212 produced the highest grain yield per plant followed by CB-214 with 36.00 grain yield per plant while Mairaj-08 produced relatively lower number of grain yield per plant (34.33) (Table 3 and Fig. 4).

All the $\mathrm{F}_{1}$ crosses lied in between the range of parental genotypes with respect grain yield per plant. Mairaj-08 $\times$ LR-1, among $\mathrm{F}_{1}$ crosses, was at the lowest position regarding grain yield per plant while maximum grain yield per plant was recorded for the cross CB-214 × LR-1 (37.67) (Table 3 and Fig. 4).

In present studies, parental genotypes which were used as females, having range of 35.00 (CB-214) to 41.00 (Mairaj-08) of 1000-grain weight as compared to males (LR-1, 36 and LR-2, 32 thousand grain weight) (Table 3, Fig. 4).

The negative estimates of heterosis and heterobeltiosis for plant height are preferred over their mid and better parent in wheat breeding because dwarfness is a desirable character (Budak and Yildirim, 1996). Almost all the hybrids showed reduction in plant height, most of which were significant too (Table 6). Maximum decrease in plant height as compared to mid parental value was observed in hybrid CB-35× LR-1 closely followed by CB-212 $\times$ LR-2, the later cross also showed the highest reduction in plant height over the better parent and standard parent (Table 6).

Maximum increase in tillers per plant over mid parent was observed in the cross CB-214 × LR-1 (26.15\%), closely followed by Cb-35 × LR-2 (24.14\%) (Table 6). While none of the crosses out yielded the better parent with respect to the higher parent. CB-212 $\times$ LR-1 showed $16.67 \%$ increase in tillers per plant as compared to the commercial parent (Mairaj-08), followed by CB-214 $\times$ LR-1 which showed $13.89 \%$ more tillers than the standard parent (Table 6). Heterosis in tiller plant per plant in wheat was also reported by many earlier researchers (Sadeque et al., 1991; Walia et al., 1993; Yu et al., 1997; Abdullah et al., 2002). So, these hybrids verified the earlier reviews.

Maximum decrease in days to heading over mid and better parent was observed in the cross Mairaj-08 $\times$ LR-2 (-6.54\% and $-15.25 \%$, respectively) (Table 6). The above mentioned cross also showed minimum significant positive increase in days to heading $(4.17 \%)$ over the standard parent (Table 6). 
Table 5. Heterosis percentage over mid parent, better parent and standard variety (Mairaj-08) for grains per spike, grain weight per spike, 1000grain weight and grain yield per plant in wheat

\begin{tabular}{|c|c|c|c|c|c|c|c|c|c|c|c|c|}
\hline \multirow{2}{*}{ CROSS } & \multicolumn{3}{|c|}{ Grains/spike } & \multicolumn{3}{|c|}{ Grain weight/spike } & \multicolumn{3}{|c|}{ 1000-Grains weight } & \multicolumn{3}{|c|}{ Grain yield/plant } \\
\hline & MP Het. & BP Het. & SP Het. & MP Het. & BP Het. & SP Het. & MP Het. & BP Het. & SP Het. & MP Het. & BP Het. & SP Het. \\
\hline CB-35 × LR1 & $5.00^{\mathrm{NS}}$ & $-4.55^{\mathrm{NS}}$ & $-14.29 * *$ & $-1.71^{\mathrm{NS}}$ & $-4.82^{\mathrm{NS}}$ & $-2.26^{\mathrm{NS}}$ & $-3.90^{\mathrm{NS}}$ & $-9.76^{*}$ & $-5.13^{\mathrm{NS}}$ & $20.63^{* *}$ & $7.55^{\mathrm{NS}}$ & $10.68 *$ \\
\hline $\mathrm{CB}-35 \times \mathrm{LR} 2$ & $3.90^{\mathrm{NS}}$ & $-9.09 *$ & $-18.37 * *$ & $0.44^{\mathrm{NS}}$ & $-5.51^{\mathrm{NS}}$ & $-2.97^{\mathrm{NS}}$ & $-4.11^{\mathrm{NS}}$ & $-14.63 * *$ & $-10.26^{*}$ & $25.58^{* *}$ & $1.89^{\mathrm{NS}}$ & $4.85^{\mathrm{NS}}$ \\
\hline CB-212 $\times$ LR 1 & $-2.56^{\mathrm{NS}}$ & $-9.52 *$ & $-22.45 * *$ & $-2.16^{\mathrm{NS}}$ & $-3.97^{\mathrm{NS}}$ & $-4.10^{\mathrm{NS}}$ & $-8.11^{\mathrm{NS}}$ & $-10.53 *$ & $-12.82 * *$ & $13.27 * *$ & $-1.77^{\mathrm{NS}}$ & $7.77^{\mathrm{NS}}$ \\
\hline $\mathrm{CB}-212 \times \mathrm{LR} 2$ & $4.00^{\mathrm{NS}}$ & $-7.14^{\mathrm{NS}}$ & $-20.41 * *$ & $2.38^{\mathrm{NS}}$ & $-2.41^{\mathrm{NS}}$ & $-2.55^{\mathrm{NS}}$ & $-5.71^{\mathrm{NS}}$ & $-13.16^{* *}$ & $-15.38 * *$ & $21.79 * *$ & $-3.54^{\mathrm{NS}}$ & $5.83^{\mathrm{NS}}$ \\
\hline $\mathrm{CB}-214 \times \mathrm{LR} 1$ & $12.20 * *$ & $0.00^{\mathrm{NS}}$ & $-6.12^{\mathrm{NS}}$ & $-35.69 * *$ & $-35.74 * *$ & $-38.19 * *$ & $-21.13 * *$ & $-22.22 * *$ & $-28.21 * *$ & $18.32 * *$ & $4.63^{\mathrm{NS}}$ & $9.71 *$ \\
\hline $\mathrm{CB}-214 \times \mathrm{LR} 2$ & $13.92 * *$ & $-2.17^{\mathrm{NS}}$ & $-8.16^{*}$ & $-6.44^{\mathrm{NS}}$ & $-9.13^{\mathrm{NS}}$ & $-12.73^{*}$ & $-9.45^{*}$ & $-13.33^{*}$ & $-22.22 * *$ & $14.94 * *$ & $-7.41^{\mathrm{NS}}$ & $-2.91^{\mathrm{NS}}$ \\
\hline CB-219 $\times$ LR 1 & $3.61^{\mathrm{NS}}$ & $-8.51 *$ & $-12.24 * *$ & $-5.78^{\mathrm{NS}}$ & $-8.46^{\mathrm{NS}}$ & $-6.65^{\mathrm{NS}}$ & $-10.53^{*}$ & $-15.00 * *$ & $-12.82 * *$ & $0.53^{\mathrm{NS}}$ & $-10.38 *$ & $-7.77^{\mathrm{NS}}$ \\
\hline CB-219 × LR2 & $2.50^{\mathrm{NS}}$ & $-12.77 * *$ & $-16.33 * *$ & $-1.98^{\mathrm{NS}}$ & $-7.49^{\mathrm{NS}}$ & $-5.66^{\mathrm{NS}}$ & $-8.33^{\mathrm{NS}}$ & $-17.50 * *$ & $-15.38 * *$ & $13.95^{* *}$ & $-7.55^{\mathrm{NS}}$ & $-4.85^{\mathrm{NS}}$ \\
\hline Mairaj-08 × LR1 & $-12.94 * *$ & $-24.49 * *$ & $-24.49 * *$ & $-5.26^{\mathrm{NS}}$ & $-7.07^{\mathrm{NS}}$ & $-7.07^{\mathrm{NS}}$ & $-14.67 * *$ & $-17.95 * *$ & $-17.95 * *$ & $-9.68 *$ & $-18.45 * *$ & $-18.45 * *$ \\
\hline Mairaj-0 $8 \times$ LR2 & $-7.32 *$ & $-22.45^{* *}$ & $-22.45^{* *}$ & $3.34^{\mathrm{NS}}$ & $-1.56^{\mathrm{NS}}$ & $-1.56^{\mathrm{NS}}$ & $-12.68 * *$ & $-20.51^{* *}$ & $-20.51 * *$ & $2.96^{\mathrm{NS}}$ & $-15.53 * *$ & $-15.53 * *$ \\
\hline
\end{tabular}

Table 6. Heterosis percentage over mid parent, better parent and standard variety (Mairaj-08) for plant height, tillers per plant, days to heading and days to anthesis in wheat

\begin{tabular}{|c|c|c|c|c|c|c|c|c|c|c|c|c|}
\hline \multirow{2}{*}{ CROSS } & \multicolumn{3}{|c|}{ Plant height } & \multicolumn{3}{|c|}{ Tillers/plant } & \multicolumn{3}{|c|}{ Days to heading } & \multicolumn{3}{|c|}{ Days to anthesis } \\
\hline & MP Het. & BP Het. & SP Het. & MP Het. & BP Het. & SP Het. & MP Het. & BP Het. & SP Het. & MP Het. & BP Het. & SP Het. \\
\hline $\mathrm{CB}-35 \times \mathrm{LR} 1$ & $-16.85 * *$ & $-39.34 * *$ & $-21.28 * *$ & $21.87 * *$ & $-17.02 * *$ & $8.33^{\mathrm{NS}}$ & $4.27 * *$ & $-1.79^{\mathrm{NS}}$ & $14.58^{* *}$ & $2.56^{\mathrm{NS}}$ & $-0.83^{\mathrm{NS}}$ & $9.09 * *$ \\
\hline $\mathrm{CB}-35 \times \mathrm{LR} 2$ & $-15.22 * *$ & $-39.06 * *$ & $-17.02 * *$ & $24.14 * *$ & $-23.40 * *$ & $0.00^{\mathrm{NS}}$ & $4.15^{* *}$ & $-4.24 * *$ & $17.71^{* *}$ & $2.07^{\mathrm{NS}}$ & $-3.91 *$ & $11.82 * *$ \\
\hline $\mathrm{CB}-212 \times \mathrm{LR} 1$ & $-17.07 * *$ & $-44.26 * *$ & $-27.66 * *$ & $21.74 * *$ & $-19.23 * *$ & $16.67 *$ & $0.00^{\mathrm{NS}}$ & $-5.56 * *$ & $23.96^{* *}$ & $0.39^{\mathrm{NS}}$ & $-5.15^{* *}$ & $17.27 * *$ \\
\hline $\mathrm{CB}-212 \times \mathrm{LR} 2$ & $-16.47 * *$ & $-44.53 * *$ & $-24.47 * *$ & $17.46^{* *}$ & $-28.85^{* *}$ & $2.78^{\mathrm{NS}}$ & $-3.28 * *$ & $-6.35 * *$ & $22.92 * *$ & $-1.52^{\mathrm{NS}}$ & $-4.41 * *$ & $18.18 * *$ \\
\hline CB-214 × LR1 & $-11.76^{* *}$ & $-38.52 * *$ & $-20.21 * *$ & $26.15^{* *}$ & $-14.58 * *$ & $13.89^{*}$ & $2.70^{*}$ & $1.79^{\mathrm{NS}}$ & $18.75^{* *}$ & $3.73 * *$ & $3.31 *$ & $13.64 * *$ \\
\hline CB-214 $\times$ LR2 & $-6.82 * *$ & $-35.94 * *$ & $-12.77 * *$ & $15.25^{*}$ & $-29.17 * *$ & $-5.56^{\mathrm{NS}}$ & $0.88^{\mathrm{NS}}$ & $-2.54^{\mathrm{NS}}$ & $19.79 * *$ & $2.42^{\mathrm{NS}}$ & $-0.78^{\mathrm{NS}}$ & $15.45 * *$ \\
\hline $\mathrm{CB}-219 \times \mathrm{LR} 1$ & $-1.64^{\mathrm{NS}}$ & $-26.23 * *$ & $-4.26^{*}$ & $6.67^{\mathrm{NS}}$ & $-25.58 * *$ & $-11.11^{\mathrm{NS}}$ & $-0.92^{\mathrm{NS}}$ & $-3.57 *$ & $12.50 * *$ & $-0.83^{\mathrm{NS}}$ & $-0.83^{\mathrm{NS}}$ & $9.09 * *$ \\
\hline CB-219 $\times$ LR2 & $-0.53^{\mathrm{NS}}$ & $-26.56 * *$ & $0.00^{\mathrm{NS}}$ & $-3.70^{\mathrm{NS}}$ & $-39.53 * *$ & $-27.78 * *$ & $-4.46^{* *}$ & $-9.32 * *$ & $11.46^{* *}$ & $-5.22 * *$ & $-7.81 * *$ & $7.27 * *$ \\
\hline Mairaj-08 × LR1 & $-8.02 * *$ & $-18.58 * *$ & $5.67 * *$ & $-28.30 * *$ & $-47.22 * *$ & $-47.22 * *$ & $-4.81 * *$ & $-11.61 * *$ & $3.13^{\mathrm{NS}}$ & $-1.30^{\mathrm{NS}}$ & $-5.79 * *$ & $3.64 *$ \\
\hline Mairaj-08 $\times$ LR2 & $-7.21 * *$ & $-19.53 * *$ & $9.57 * *$ & $-27.66 * *$ & $-52.78 * *$ & $-52.78 * *$ & $-6.54 * *$ & $-15.25^{* *}$ & $4.17 *$ & $-5.04 * *$ & $-11.72 * *$ & $2.73^{\mathrm{NS}}$ \\
\hline
\end{tabular}

$* *, *$ is equal to significant at $0.01,0.001$ respectively and NS showing non significant 
The outcome of the present study are in accordance with the results of Sadeque et al. (1991), Murai (1998), Wu et al. (2001) and Baric et al. (2004) who described that negative heterosis in days to heading may be an effective selection criteria for development of early maturing short durational cultivars in wheat.

The highest reduction in days to anthesis with respect to mid and better parent was recorded for the cross Mairaj-08 $\times$ LR-2 (Table 6). All the crosses showed increase in days to anthesis over the standard parent, while minimum increase was revealed from the above mentioned cross (Table 6 ). These findings are in accordance with previous reports by Chowdhry et al. (2005), Farooque et al. (2005), Ullah et al. (2006) and Boche (2013).

All the crosses showed negative heterosis over mid, better and standard parental value for spike length, however minimal decrease, also non-significant, in spike length as compared to mid and better parental value was recorded for the cross CB-219 $\times$ LR-1 (Table 4). While CB-212 $\times$ LR-1 showed minimum non-significant decrease in spike length as compared to the standard parent (Table 4). These significant outcomes are in agreement with those of Masood et al. (2005), Ilker et al. (2010) and Mahpara et al. (2015). Similar findings had been reported by researchers like, Walia et al. (1993), Li et al. (1997) and Hassan et al. (2007).

The genotypes produced as $\mathrm{F}_{1}$ showed a range of 22 to 33 days for grain filling including Mairaj-08 $\times$ LR-1 at the lower extreme and CB-212 $\times$ LR-1 at the higher extreme (Table 2 and Fig. 2). Grain filling period was considerably reduced as compared to mid and better parental value for the cross Mairaj-08 $\times$ LR-1 i.e. $-15.38 \%$ and $-26.67 \%$, respectively (Table 4). While the same cross was at par the standard parent for the trait. These results were got supported by earlier reports of Murai (1998), Wu et al. (2001) and Baric et al. (2004), Ullah et al. (2006) and Beche et al. (2013).

The single cross Mairaj- $08 \times$ LR-2 was considered the most desirable genotype towards early maturity as it showed the highest heterotic effects over mid and better parent $(-5.48 \%$ and $-13.75 \%$, respectively (Table 4). While none of the crosses showed reduction in maturity period as compared to standard parent, however the above mentioned cross showed minimum significant increase in maturity days over the commercial variety i.e. $4.55 \%$ (Table 4). These results of current study were supported by Farooque et al. (2005), Ullah et al. (2006), Hassan et al. (2007) and Boche (2013) who concluded that genotypes taking less number of days for maturity might possess the potential of yielding short durational pure lines.

The highest heterotic effects over mid parental value were observed for the cross CB-214 $\times$ LR-2 (13.92\%), followed by CB-214 × LR-1 (12.20\%) (Table 5). None of the crosses showed increase in grains per spike over better and standard parent, however the later mentioned cross exhibited minimum and non-significant decrease in grains per spike as compared to better parent and standard variety. Tiwari and Chakraborty (1992), Larik et al. (1999), and Hassan et al. (2007) observed similar results. These is agreement in earlier studies (Çifci and Yaðdi, 2007) but less than that of Fonseca and Patterson (1968) who found $100 \%$ heterobeltiosis in the crosses obtained from genetically different parents. On the other hand, Baric et al. (2004) found negative heterosis values in terms of number of grains spike in bread wheat crosses.

All the crosses exhibited negative values of heterosis over mid, better and standard parent except Mairaj-08 $\times$ LR-2 which presented positive yet non-significant heterosis over mid parental value (3.34\%) (Table 5). The above mentioned cross also showed minimum and non-significant decrease as compared to better and standard parent with respect to grain weight per spike. These results were got supported by earlier reports of 
Murai (1998), Wu et al. (2001), Abdullah et al. (2002), Farooque et al. (2005), Akbar et al. (2007), Ullah et al. (2006) and Boche, (2013).

Maximum significant increase in grain yield per plant, with respect to mid parental value, was recorded for the cross CB-35 $\times$ LR-2 (25.58\%), followed by the cross CB-35 $\times$ LR-1 (20.63\%) (Table 5). The later cross also showed maximum yet non-significant value for heterobeltiosis and the highest significant value $(10.68 \%)$ for standard heterosis (Table 5). Results of heterosis in grain yield per plant were found in agreement with those of Wu et al. (2001), Abduulah et al. (2002), Faroque et al. (2005), Ullah et al. (2006), Akbar et al. (2007), Kumar et al. (2013) and Mahpara et al. (2015).

\section{Conclusion and Recommendations}

The research made use of semi dwarf lines to cross with land races in order to increase grain yield and to obtain noval germplasm resistant to lodging, which to good extent. It is recommended that since this research provides a baseline that could attract researchers to follow such and different crossing combinations with local land races to obtain improved varieties with significant yield for increased farmer premiums.

\section{REFERENCES}

[1] Abdullah, G. M., Khan, A. S., Ali, Z. (2002): Heterosis study of certain important traits in wheat. - Int. J. Agric. Bio. 4(3): 326-328.

[2] Akbar, M., Khan, M. A., Rehman, A., Ahmed, N. (2007): Heterosis and heterobeltiosis for improvement of wheat grain yield. - AGRIS 45(2): 87-94.

[3] Baric, M., Sarcevic, H., Keresa, S. (2004): Analysis of yield components of F1 hybrids of crosses between spring and winter wheat types (Triticum aestivum L.). - J. Agric. Conspec. Sci. 69: 11-15.

[4] Beche, E., Lemes, C., Pagliosa, E. S., Capelin, M. A., Franke, J., Matei, G. (2013): Hybrid performance and heterosis in early segregant populations of Brazilian spring wheat. Australian J. Crop Sci. 7(1): 51-57.

[5] Belderok, B. (2000): Bread-Making Quality of Wheat: A Century of Breeding in Europe. - Kluwer Academic Publishers, Netherlands, 34.

[6] Briggle, L. W. (1963): Heterosis in wheat. A review. - Crop Sci. 3: 407-412.

[7] Budak, N., Yildirim, M. B. (1996): Heterosis in bread wheat (Triticum aestivum L.). Turkish J. Agri. Forest. 20: 345-7.

[8] Chowdhry, M. A., Parveen, N., Khaliq, J., Kashif, M. (2005): Estimation of heterosis for yield and yield component in bread wheat. - J. Agri \& Soc Sci. 1(4): 304-308.

[9] Cifci, E. A., Yagdi, K. (2007): Determination of some agronomic traits by diallel hybrid analysis in common wheat (Triticum aestivum L.). - Tarim Bilimleri Dergisi 13(4): 355364.

[10] Farooque, J., Habib, I., Khaliq, I. (2005): Diallel analysis to predict utilization of heterosis and heterobeltiosis yield and yield component of bead wheat. - J. Agri Res. 43: 171-182.

[11] Fonseca, A., Patterson, F. L. (1968): Hybrid vigor in a seven parent diallel cross in common winter wheat (T. aestivum L.). - J. Crop Sci. 8: 85-88.

[12] Freeman, G. F. (1919): Heredity of quantitative characters in wheat. - Genetics 4(1): 1-93.

[13] Giraldo, P., Benavente, E., Manzano-Agugliaro, Gimenez, E. (2019): Worldwide Research Trends on Wheat and Barley: A Bibliometric Comparative Analysis. - Agronomy 9: 352.

[14] GOP. (2019): Agriculture: Economic Survey of Pakistan 2018-2019. - Ministry of Food and Agriculture, Government of Pakistan, Islamabad. 
[15] Hassan, G., Mohammad, F., Afridi, S. S., Khalil, I. H. (2007): Combining ability in the F1 generations of diallel cross for yield and yield components in wheat. - Sarhad J. Agri. 23(4): 937-942.

[16] Hrivna, L., Zigmundová, V., Burešová, I., Maco, R., Vyhnánek, T., Trojan, V. (2018): Rheological properties of dough and baking quality of products using coloured wheat. Plant Soil Environ. 64: 203-208.

[17] Ihsanullah, J., Taj, A., Khan, F. H., Khan, I. A. (2002): Effect of Sowing Dates on Yield and Yield Components of Mash Bean. - Asian J. Plant Sci. 1: 622-624.

[18] Ilker, E., Tonk, F. A., Tosun, M. (2010): Heterosis for yield and its components in bread wheat crosses among powdery mildew resistant and susceptible genotypes. - Pak. J. Bot. 42(1): 513-522.

[19] Khan, A. K., Salim, I., Ali, Z. (2003): Heritability of Various Morphological Traits in Wheat. - Int. J. Agric. Biol. 5: 138-140.

[20] Kumar, A., Mishra, V. K., Vyas, R. P., Singh, V. (2013): Heterosis and combining ability analysis in bread wheat (Triticum aestivum L.). - J. Plant Breed. Crop Sci. 3: 209-217.

[21] Larik, A. S., Mahar, A. R., Kakar, A. A., Shafkh, M. A. (1999): Heterosis, inbreeding depression and combining ability in Triticum aestivum L. - Pak. J. Agri. Sci. 36(1-2): 3944.

[22] Li, Y. C., Peng, J. H., Liu, Z. Q. (1997): Heterosis and combining ability for plant height and its components in hybrid wheat with Triticum timopheevi cytoplasm. - Euphytica 95: $337-45$

[23] Mahpara, S., Ali, Z., Farooq, J., Hussain, S., Bibi, R. (2015): Heterosis and Heterobeltiosis analysis for spike and its attributes in different Wheat crosses. - Pak. J. Nutr. 14(7): 396400.

[24] Masood, J., Ghulam, H., Khalil, I. H., Raziuddin (2005): Estimates of heterosis and heterobeltiosis for morphological traits in wheat (Triticum aestivum L.). - Pak. J. Biol. Sci. 8(9): 1261-1264.

[25] Matzinger, D. F., Mannand, T. J., Cockerham, C. C. (1962): Diallel cross in Nicotiana tabacum. - Crop Sci. 2: 238-286.

[26] Mazurek, J., Sabat, A. (1984): Effect of sowing rate and nitrogen fertilizer application on yields of some triticale cultivars. - Pamie hook tnik Pulawski 83: 85-93.

[27] Moon, D. (2008): In the Russian Steppes: The Introduction of Russian Wheat on the Great Plains of the United States of America. - J. Glob Hist. 3: 203-225.

[28] Murai, K. (1998): F1 Seed production efficiency by photoperiod sensitive, cytoplasmic male sterility and performance of F1 hybrid lines in wheat. - Breed. Sci. 48: 35-40.

[29] Ozgen, M. (1989): Kışlık Ekmeklik Buğdayda (Triticum aestivum L.) MelezGücü. Turkish. J. Agric. For. 13(3): 1190-1201.

[30] Sadeque, Z., Bhowmik, A., Ali, M. S. (1991): Estimates of heterosis in wheat (Triticum aestivum L.). - Ann. Bangla Agri. 1: 75-79.

[31] Saleem, M., Hussain, S. (1988): Estimation of heterosis in yield components of wheat. Pak. J. Agric. Res. 9: 1-5.

[32] Shewry, P. R. (2009): Wheat. - J. of Exp Bot. 60: 1537-1553.

[33] Steel, R. G. D., Torrie, J. H. (1980): Principles and procedures of statistics. - 2nd ed. McGraw-Hill Book Company Inc., New York.

[34] Tiwari, V., Chakraborty, S. K. (1992): Heterosis studies in bread wheat (Triticum aestivum L. em. Thell.). - Envi Eco. 10: 197-202.

[35] Tsenov, N., Atanasova, D., Todorov, I., Dochev, V. (2008): Environmental Effect on Common Winter Wheat Productivity. - Proceedings of 18th EUCARPIA General Congress, Valencia, 9-12 Sept. 2008, 480-484.

[36] Ullah, I., Ahmad, H., Muhammad, F., Din, S. U., Hassan, G., Gul, R. (2006): Evaluation of the heterotic and heterobeltiotic potential of wheat genotypes for improved yield. Pakistan J. Bot. 38(4): 1159-1167. 


$$
\text { - } 6689 \text { - }
$$

[37] Walia, D. P., Tashi, D., Plaha, P., Chaudhary, H. K. (1993): Gene action and heterosis in bread wheat. - Ludhiana Symp. 2: 23-4.

[38] Wu, L. M., Ni, Z. F., Wang, Z. K., Lin, Z., Sun, Q. X. (2001): Relationship between differential expression patterns of multigene families and heterosis in a wheat diallel crosses. - Acta Genetica Sinica 28(3): 256-266.

[39] Wynne, J. C., Emery, D. A., Rice, P. H. (1970): Combining ability estimation in Arachis hypogaea L. 11. Field performance of F1 hybrids. - Crop Sci. 10: 713-715.

[40] Yu, Y. J., Chen, Q. S., Yin, J. Y. (1997): A study on the use of wheat heterosis in the Beijing area- An analysis of heterosis in certain important wheat varieties and lines. Beijing Agric. Sci. 15: 13-15. 